\title{
Analysis of the multi-stage desiccant cooling system performance in Wroctaw (Poland)
}

\author{
Anna Pacak $^{1, *}$, Aleksandra Cichoń $^{1}$, Demis Pandelidis ${ }^{1}$, and Sergey Anisimov ${ }^{1}$ \\ ${ }^{1}$ Wrocław University of Science and Technology, Faculty of Environmental Engineering, Department \\ of Air Conditioning, Heating, Gas Engineering and Air Protection, ul. Norwida 4/6, \\ 50-373 Wroclaw, Poland
}

\begin{abstract}
In this study, the application potential of desiccant cooling system with indirect evaporative precooling is analyzed for moderate climatic conditions. Wrocław (Poland) was selected as a representative city. On the base of summer season weather parameters different system running modes were proposed such as cooling and dehumidification mode (Mode 1) and only cooling mode (Mode 2). The average month Thermal and Electrical COP were established for selected climatic conditions. It was concluded that proposed system allows to cool the air without occurrence of condensation in Mode 2 with high average monthly electrical $\mathrm{COP}\left(\mathrm{COP}_{\mathrm{el}}=62.2\right.$ in August). On the other hand when dehumidification is needed, system operates in Mode 1 and obtains relatively high average Thermal $\mathrm{COP}$ values $\left(\mathrm{COP}_{\text {th }}=2.2\right)$.
\end{abstract}

\section{Introduction}

Indirect evaporative cooling (IEC) is currently one of the most promising solutions for air conditioning. These devices provide the airflow temperature decrease, by sensible cooling, without adding any moisture to the air. One of the best methods of IEC approaching the low supply air temperatures such as dew point temperature, is the novel thermodynamic cycle, known as the Maisotsenko cycle (M-cycle). On the other hand, in typical direct evaporative coolers, humidity ratio of the treated airflow increases during cooling process, and a wet-bulb temperature is a limitation of this process. M-Cycle heat and mass exchangers (HMX) are already produced for air conditioning systems by Coolerado Corporation [1]. The main advantage of the M-Cycle units over typical vapor-compression systems is that it utilizes significantly less electricity [2]. It is the reason why these devices are treated as an environmental friendly solution for cooling energy production. Individual devices based on the M-Cycle technology are implemented for systems which operate especially in hot and dry area for now [3]. In humid and moderate climatic conditions there is a necessity to control the humidity level of the supply airflow. It is possible to use M-Cycle IEC devices in those areas also. In such a climatic conditions they need to cooperate with some devices which provide the outdoor air dehumidification. The most representative solid dehumidification units are the thermally driven desiccant wheels [4]. There are two main advantages of solid desiccant systems confirming its cost saving potential. They may use

\footnotetext{
* Corresponding author: anna.pacak@pwr.edu.pl
} 
solar or waste thermal energy for heating the regeneration air which is used for desorption of desiccant wheel, and they allow to control the temperature and humidity of the supply airflow independently $[5,6]$. Either solid desiccant which usually consists of desiccant wheel and cooling device, or M-cycle dew point evaporative coolers has been extensively reported in the literature. Chaudhary et. al. [7] proposed a solid desiccant cooling system equipped with a cross-flow M-Cycle unit and solar power as a heat source. They analyzed its operation experimentally considering the performance indicators such as dehumidification effectiveness, dew point effectiveness, Thermal COP, and cooling capacity. The results show that this system reaches an average Thermal COP equal to 0.91 for analyzed hot and humid climatic conditions. Comino et. al. [8] established the annual energy consumption of a hybrid system with a desiccant wheel activated at low temperatures and an IEC for 6 climate zones. The system was compared to the direct expansion (DX) system and it represents a significant energy savings, up to $46.8 \%$. The authors concluded that this system has a great potential to reduce energy costs and ensure proper thermal comfort air conditioning spaces concurrently. Shahzad et. al. [9] also performed an experiment in which the performance investigation of a solid desiccant dehumidifier integrated with Maisotsenko cycle (M-Cycle) was presented. The comparison of proposed system to the typical desiccant air conditioning system shows that it is around $60-65 \%$ more efficient in terms of Thermal COP.

\section{Proposed system description}

The interest in desiccant cooling systems is increasing due to its ability to produce cooling utilizing thermal energy. Moreover, the energy required to regenerate the desiccant wheel in the summer may come from many energy sources like solar collectors, heat pumps or waste heat. In the case of a conventional desiccant cooling system, the end-point air treatment is limited by the humidification of the airflow in direct evaporative coolers. In this study, a novel system which is a simple way of improving the M-Cycle desiccant system performance is proposed. The new system uses precooling of the air stream before the dehumidification process. In this system, the ambient air is cooled two times, both before the dehumidification process and after. It allows lower supply air temperature and humidity ratios to be obtained [10]. The proposed system consists of a combination of two indirect evaporative air coolers combined with a desiccant wheel (see Fig. 1).

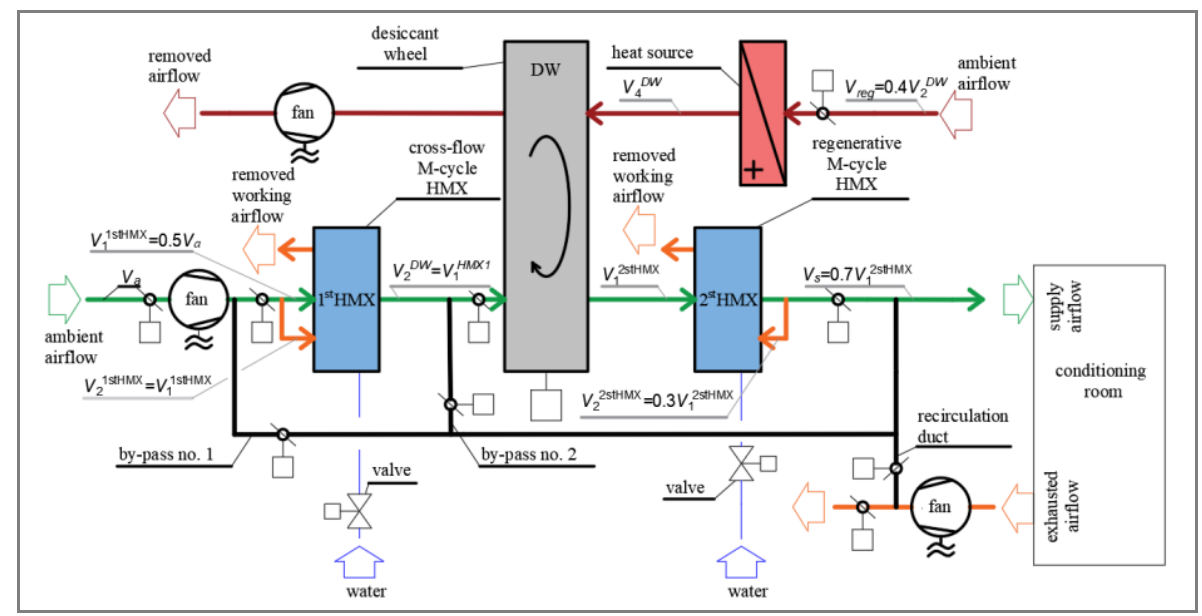

Fig. 1. Analyzed system scheme. 
The first cross-flow M-Cycle unit is located before the desiccant wheel, to initially precool the outdoor air, before it enters the dehumidification section. The second regenerative M-Cycle unit is located after the desiccant wheel and it realized the post cooling of the process airflow. The aim of this study is to establish the system performance in moderate climatic conditions numerically, on the base of the real outdoor air conditions. To do that two key performance indicators are proposed those are: Thermal Coefficient of Performance and Electric Coefficient of Performance.

\section{Methods}

Performance of M-Cycle regenerative air cooler, cross-flow M-cycle air cooler and desiccant wheel were simulated using original $\varepsilon$-NTU models. These models are created with an assumption that the airflow is treated as gaseous fluid, which has temperature, velocity and mass transfer potential equal to bulk average values in sections normal to the plate surface of heat exchanger. Models equations, validation of these models are presented in author's previous works $[10,11]$. Main system components characteristics are presented in Table 1.

Table 1. Main system components operating characteristics [10].

\begin{tabular}{|c|c|c|c|}
\hline \multicolumn{2}{|c|}{$\begin{array}{c}\text { Indirect evaporative air coolers } \\
\text { parameters }\end{array}$} & \multicolumn{2}{c|}{ Desiccant wheel parameters } \\
\hline Cross-flow M-Cycle HMX & & $\begin{array}{c}\text { Specific heat capacity (silica gel), } \\
\mathrm{J} /(\mathrm{kg} \text { K) }\end{array}$ & 750 \\
\hline Working to intake air ratio & 1.0 & Channel type & Sinusoidal \\
\hline $\mathrm{NTU}_{1}$ & 8 & Channel height, mm & 1.24 \\
\hline $\mathrm{NTU}_{2}$ & 8 & Channel width, mm & 2.21 \\
\hline & & Wall thickness, mm & 0.30 \\
\hline $\begin{array}{c}\text { Working to intake air ratio } \\
\text { (regenerative M-Cycle HMX) }\end{array}$ & 0.3 & Channel length, m & 0.1 \\
\hline $\mathrm{NTU}$ & 10 & $\begin{array}{c}\text { Wheel diameter, } \mathrm{m} \\
\text { regent of wheel used for }\end{array}$ & 0.5 \\
\hline $\mathrm{NTU}_{2}$ & 16.7 & Rotational speed, cycles/hour & 40 \\
\hline
\end{tabular}

\section{Selected outdoor air parameters}

Authors dedicate the system especially for moderate climatic conditions. Wrocław (Poland) is a representative city for which a selected summer season outdoor air parameters has been analyzed in this study. Each system configuration can work in 3 different operation modes. The mode selection depends on the ambient air parameters which are presented in Table 3 . The limits were established with an assumption that the comfort indoor air parameters are in temperature range between $20^{\circ} \mathrm{C}$ and $25^{\circ} \mathrm{C}$ and humidity ratio below $12 \mathrm{~g} / \mathrm{kg}$. The maximum humidity ratio is established on the base of an assumption that the share of sensible heat loads in total heat loads is about 0.8 . That is why, $11 \mathrm{~g} / \mathrm{kg}$ is the maximum humidity ratio of the supply airflow which enables to maintain a typical indoor thermal comfort. 
Table 2. Conditions for operation modes.

\begin{tabular}{|c|c|c|}
\hline Mode 1 & Mode 2 & Mode 3 \\
\hline $\begin{array}{c}\text { Cooling and } \\
\text { dehumidification }\end{array}$ & Cooling & Ventilation mode \\
\hline$t_{a} \geq 20^{\circ} \mathrm{C} \pm 0.5^{\circ} \mathrm{C}$ \\
$\begin{array}{c}\text { and } \\
x_{a} \geq 11 \mathrm{~g} / \mathrm{kg} \pm 0.5 \mathrm{~g} / \mathrm{kg}\end{array}$ & $\begin{array}{c}t_{a} \geq 20^{\circ} \mathrm{C} \pm 0.5^{\circ} \mathrm{C} \\
\text { and }\end{array}$ & $t_{a}<21 \mathrm{~g} / \mathrm{kg} \pm 0.5 \mathrm{~g} / \mathrm{kg}$
\end{tabular}

After the hourly analysis of the outdoor air parameters such as air temperature and humidity ratio, the amount of mode working hours was specified (See. Fig. 2). It may be observed that during selected months in year 2018, System would work in Mode 2 for most of the summer season. It means that, the air is cooled down only in $1^{\text {st }} \mathrm{HMX}$ (see Fig. 1) and next it is bypassed using the bypass no. 2 . Mode 1 uses each device of the system ( $1{ }^{\text {st }} \mathrm{HMX}$, desiccant wheel and $2^{\text {st }} \mathrm{HMX}$ ) and its operation hours makes up about $30 \%$ of total working hours in August, about $20 \%$ in July and the least $13 \%$ in June. In polish climatic conditions there are the days and hours when the air needs to be delivered to the room but the temperature and humidity ratio are low enough to cover sensible and latent heat loads. In such operating conditions the bypass no 3 is used and system works in Mode 3. What is more, in Mode 3, the recirculation duct may be used. When the ambient air temperature is to low, the air may be mixed with the exhausted air and delivered to the air conditioning space (see Fig. 1). The amount of mode working hours is specified in Fig. 2. It has to be underlined that authors analyzed 920 hours in total.

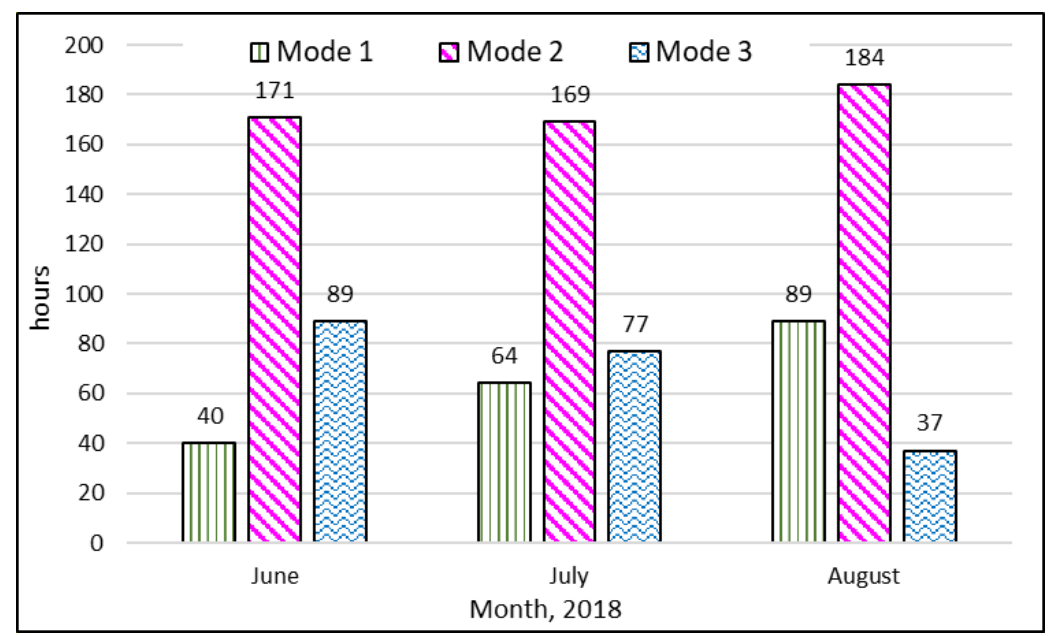

Fig. 2. System operation modes for selected summer operating conditions for Wrocław (Poland).

For considered climatic conditions, proposed system operates in Cooling mode (Mode 2) mostly. There is a significant advantage of such a solution. It enables to cool the air sensibly down without occurrence the condensation process. It is a main difference of such a solution comparing to the typical vapor-compression systems in which usually decreasing temperature is connected with decreasing the humidity ratio of the treated airflow. It pushes up the energy demand for air conditioning system. It is the fact that M-Cycle evaporative coolers produce the cooling energy with high energy efficiency. To establish the system efficiency for selected climatic zone three month average $\mathrm{COP}_{\mathrm{el}}$ factor is determined for Cooling mode (Mode 2). In moderate climates there are days where the dehumidification of the ambient airflow is necessary. In such a conditions, the proposed device is working in Mode 1 in which the cooling and dehumidification processes run separately. To establish 
the effectiveness of this mode, two average key performance indicators $\mathrm{COP}_{\mathrm{el}}$ and $\mathrm{COP}_{\text {th }}$ (Thermal Coefficient of Performance) were calculated.

\section{System performance}

In this section, the results of the system performance analysis based on the computational simulations are presented. Below, the basic equations which were used for calculation of chosen key performance indicators. System cooling capacity is calculated on the base of the outdoor air temperature and humidity ratio measured in Wroclaw (Poland) which is located in moderate climatic conditions.

The Thermal Coefficient of Performance was calculated using the following formula:

$$
\mathrm{COP}_{\mathrm{th}}=\frac{\Phi}{P}
$$

Where the cooling capacity of the supply airflow was calculated using the formula:

$$
\Phi=V_{1 o}^{2^{\text {st }} \mathrm{HMX}} \rho\left(i_{E}-i_{1 o}^{2^{\text {st }} \mathrm{HMX}}\right)
$$

Energy for regeneration purposes was calculated from the equation:

$$
P=V_{4} \rho c_{p}\left(t_{r e g}-t_{E}\right)
$$

The Electrical Coefficient of Performance was calculated using the equation:

$$
\mathrm{COP}_{\mathrm{el}}=\frac{\Phi}{N}
$$

Where the energy consumption by fan was calculated using the equation:

$$
N=\Delta p V_{1 i}^{\mathrm{It}^{\mathrm{st}} \mathrm{HMX}} / \eta
$$

A fan efficiency of $\eta=0.4$ was used.

In Table 3 there are considered ranges of ambient, exhausted and regeneration air parameters for which the simulations of system performance were conducted.

Table 3. Air parameters for simulations.

\begin{tabular}{|c|c|c|c|}
\hline Ambient airflow: & $V_{a}=1000 \mathrm{~m}^{3} / \mathrm{h}$ & Minimum value & Maximum value \\
\hline \multicolumn{4}{|c|}{ Assumed exhausted air parameters } \\
\hline Temperature & $t_{C R}$ & $20^{\circ} \mathrm{C}$ & $25^{\circ} \mathrm{C}$ \\
\hline Humidity ratio & $R H_{C R}$ & $40 \%$ & $60 \%$ \\
\hline \multicolumn{4}{|c|}{ Assumed regeneration air parameters } \\
\hline Temperature & $t_{4}^{D W}$ & $45^{\circ} \mathrm{C}$ & $45^{\circ} \mathrm{C}$ \\
\hline Humidity ratio & $x_{4}^{D W}=x_{a}$ & $10.5 \mathrm{~g} / \mathrm{kg}$ & $16.2 \mathrm{~g} / \mathrm{kg}$ \\
\hline \multicolumn{4}{|c|}{ Ambient air parameters during selected period of time } \\
\hline Temperature & $t_{a}$ & 12.9 & 33.4 \\
\hline Humidity ratio & $x_{a}$ & $10.5 \mathrm{~g} / \mathrm{kg}$ & $16.2 \mathrm{~g} / \mathrm{kg}$ \\
\hline
\end{tabular}

Table 4. Obtained $\mathrm{COP}_{\text {th }}$ and $\mathrm{COP}_{\mathrm{el}}$ for system operation modes.

\begin{tabular}{|c|c|c|c|c|c|c|}
\hline & \multicolumn{3}{|c|}{ Mode 1 } & \multicolumn{3}{c|}{ Mode 2 } \\
\hline running hours & \multicolumn{3}{|c|}{ J3 } & \multicolumn{3}{c|}{} \\
\hline Month & June & July & August & June & July & August \\
\hline average COP & 1.5 & 1.8 & 2.2 & - & - & - \\
\hline average COP & 18.0 & 18.4 & 19.1 & 59.4 & 62.0 & 62.2 \\
\hline $\begin{array}{c}\text { maximum } \\
\text { COP }_{\text {th }}\end{array}$ & 2.7 & 2.4 & 3.7 & & & \\
\hline
\end{tabular}




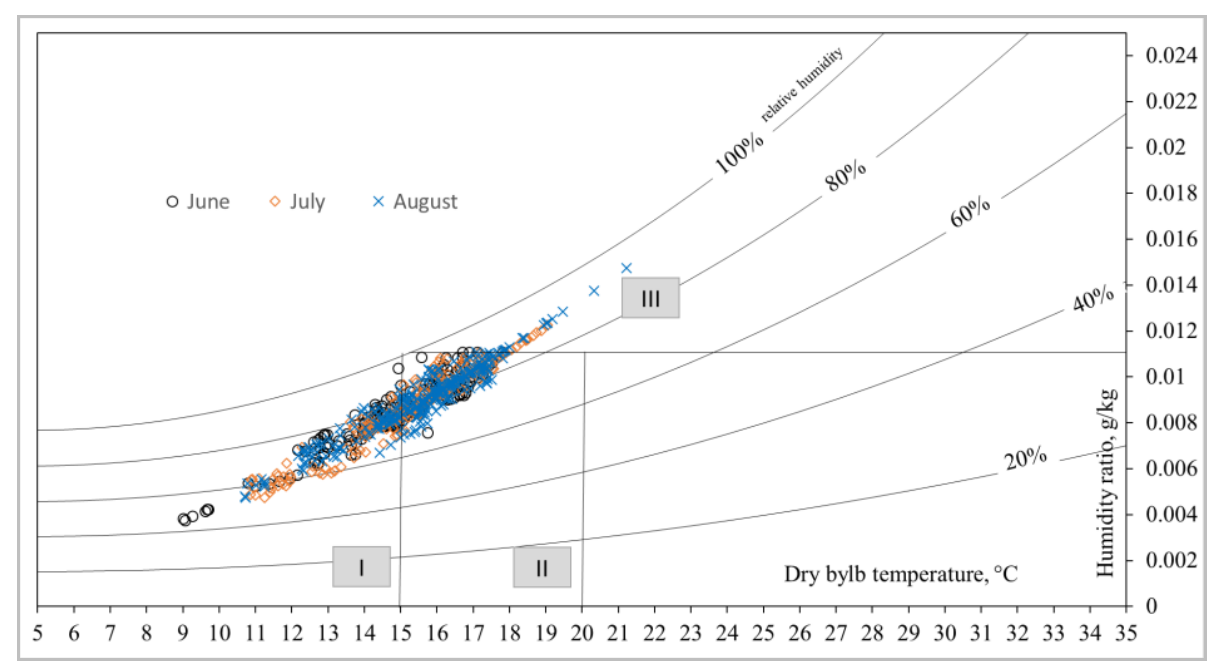

Fig. 3. Supply airflow parameters on psychometric chart.

According to the data presented in Table 4 proposed system represents high electrical performance in Cooling Mode 2 because only $1^{\text {st }} \mathrm{HMX}$ is in operation. On the other hand, the month average monthly thermal Coefficient of Performance is above 1.0 and it equals 1.5 in June, 1.8 in July and 2.2 in August. The higher outdoor air temperature the higher system $\mathrm{COP}_{\text {th }}$ is observed. It is because of the fact that the desiccant wheel is regenerated by the heated ambient airflow. The calculations allowed to establish the COP values for each working hour during selected summer season. In Table 5 the appearance of $\mathrm{COP}_{\text {th }}$ is presented and it may be noticed that the $\mathrm{COP}_{\text {th }}$ is higher than 3 during $11 \%$ of operation hours (in Mode 1), it is between 2 and 3 during 28\% of operation hours and between 1 and 2 during $55 \%$ of operation hours. The maximum hourly $\mathrm{COP}_{\text {th }}$ value equals 3.73 .

Table 5. $\mathrm{COP}_{\text {th }}$ appearance.

\begin{tabular}{|c|c|}
\hline COP $_{\text {th }}$ & Percent of hours appearance in working Mode 1 \\
\hline$[1-2)$ & $55 \%$ \\
\hline$[2-3)$ & $28 \%$ \\
\hline$\geq 3$ & $11 \%$ \\
\hline
\end{tabular}

In Fig. 3 obtained supply airflow parameters for selected months are presented. It may be seen that analyzed system for considered regeneration air temperature for most cases is able to assimilate latent and sensible heat loads (see Fig. 3 zone II). The supply airflow parameters included in zone III in psychometric chart would not provide the comfort indoor conditions. In such situations a higher regeneration temperature is necessary to decrease the humidity ratio of the supply airflow. When the supply air temperature is too low (see zone I) the system performance regulation is necessary. It can be realized by mixing the air after $2^{\text {st }} \mathrm{HMX}$ with the hot air after the desiccant wheel in Mode 1 . In Mode 2 when the supply air temperature is below $15^{\circ} \mathrm{C}$ the $1^{\text {st }} \mathrm{HMX}$ may be bypassed by the part of the airflow and mixed after the heat and mass exchanger. Second possibility for temperature increase in Mode 2 is to recirculate the exhausted air. 


\section{Conclusions}

This paper presents a performance analysis of a novel desiccant air conditioning system with indirect evaporative precooling for selected real moderate climatic conditions in summer season. Authors proposed 3 different system running modes. Mode 1 provides cooling and dehumidification of the ambient airflow. Mode 2 provides only cooling the ambient airflow and Mode 3 is a ventilation mode in which the air treatment such as cooling or dehumidification is unnecessary. For each mode the average key performance indicators were calculated on the base of simulation results. Those are: Thermal Coefficient of Performance $\left(\mathrm{COP}_{\text {th }}\right)$ and Electrical Coefficient of Performance (COPel). During 55\% of Mode 1 operational hours COPth is between 1.0 and 2.0, during 28\% between 2.0 and 3.0 and during $11 \%$ the COPth is above 3.0. The maximum hour COPth equals 3.73. For most of the ambient airflow parameters during summer season in Wroclaw (Poland) the system is able to provide the sufficient supply airflow parameters. Nevertheless, the in some cases the regeneration temperature equal to $45^{\circ} \mathrm{C}$ is inadequate and it needs an increment to provide proper supply airflow humidity ratio.

One of the co-authors, Demis Pandelidis, received financial support for his research from resources for scientific work for years 2016-2019 from Polish Ministry of Science and High Education (program "Iuventus Plus"), project number IP2015 058274 and from Polish National Agency for Academic Exchange (Bekker program), agreement number PPN/BEK/2018/1/00347/U/00001.

$\mathrm{COP}_{\mathrm{el}}$ - Electrical Coefficient of Performance, $\mathrm{COP}_{\mathrm{th}}-$ Thermal Coefficient of Performance, $i$ - enthalpy; $\mathrm{kJ} / \mathrm{kg} ; N$ - energy consumption by fan, W; $P$ - energy for regeneration purposes, W; $\mathrm{RH}$ - relative humidity; $t$ - temperature, ${ }^{\circ} \mathrm{C} ; V$ - airflow, $\mathrm{m}^{3} / \mathrm{h} ; \mathrm{x}$ - humidity ratio, $\mathrm{g} / \mathrm{kg} ; \Phi$ - cooling capacity, W; $\Delta p$ - Pressure, Pa; $\rho$ - Air density, $\mathrm{kg} / \mathrm{m}^{3}$, Subscripts: $i$ - inlet; $o$ - outlet; reg - regeneration. Acronyms: $1^{\text {st }} \mathrm{HMX}-$ cross-flow heat and mass exchanger; $2^{\text {st } H M X ~-~ r e g e n e r a t i v e ~ h e a t ~ a n d ~ m a s s ~ e x c h a n g e r ; ~} a$ - ambient; $C R$ - conditioning room; DW - desiccant wheel, $s$ - supply NTU - Number of Transfer Units; 1 - product; 2 - working; 3 -process; 4 -regeneration.

\section{References}

[1] B. Weerts, CU Scholar NSIDC Green Data Center Project: Coolerado and Modeling an Application of the Maisotsenko Cycle (2017)

[2] Inernational Energy Agency, The Future of Cooling (2018)

[3] W. Gao, W. Worek, V. Konduru, K. Adensin, Energy Build. 86 (2015)

[4] H. Sadighi Dizaji, E. J. Hu, L. Chen, Energy, 156 (2018)

[5] D. B. Jani, M. Mishra, P. K. Sahoo, Renew. Sustain. Energy Rev. 60 (2016)

[6] D. La, Y. J. Dai, Y. Li, R. Z. Wang, T. S. Ge, Renew. Sustain. Energy Rev. 14 (2010)

[7] G. Qadar Chaudhary, M. Ali, N. A. Sheikh, S. I. ul H. Gilani, S. Khushnood, Appl. Therm. Eng. 140 (2018)

[8] F. Comino, M. Ruiz de Adana, F. Peci, Appl. Therm. Eng. 131 (2018)

[9] M. Kashif Shahzad, M. Ali, N. Ahmed Sheikh, G. Qadar Chaudhary, M. Shahid Khalil, T. U. Rashid, Appl. Therm. Eng. 128 (2018)

[10] D. Pandelidis, A. Pacak, A. Cichoń, S. Anisimov, P. Drąg, B. Vager, V. Vasilijev, Energy Convers. Manag. 177 (2018)

[11] D. Pandelidis, S. Anisimov, W. M. Worek, P. Drąg, Energy Build. 123 (2016) 